\title{
The crucial role in controlling the dynamic properties of polyester-based epoxy vitrimers: the density of exchangeable ester bonds (v)
}

Mao Chen*a, Hongwei Si ${ }^{b}$, Huan Zhang ${ }^{b}$, Lin Zhou ${ }^{b}$, Yeping $W u^{a}$, Lixian Song ${ }^{b}$, Ming

Kang $^{b}$, and Xiuli Zhao*a

anstitute of Chemical Materials, China Academy of Engineering Physics, Mianyang 621900, China.

'State Key Laboratory of Environment-friendly Energy Materials, Southwest University of Science and Technology, Mianyang, 621010, China.

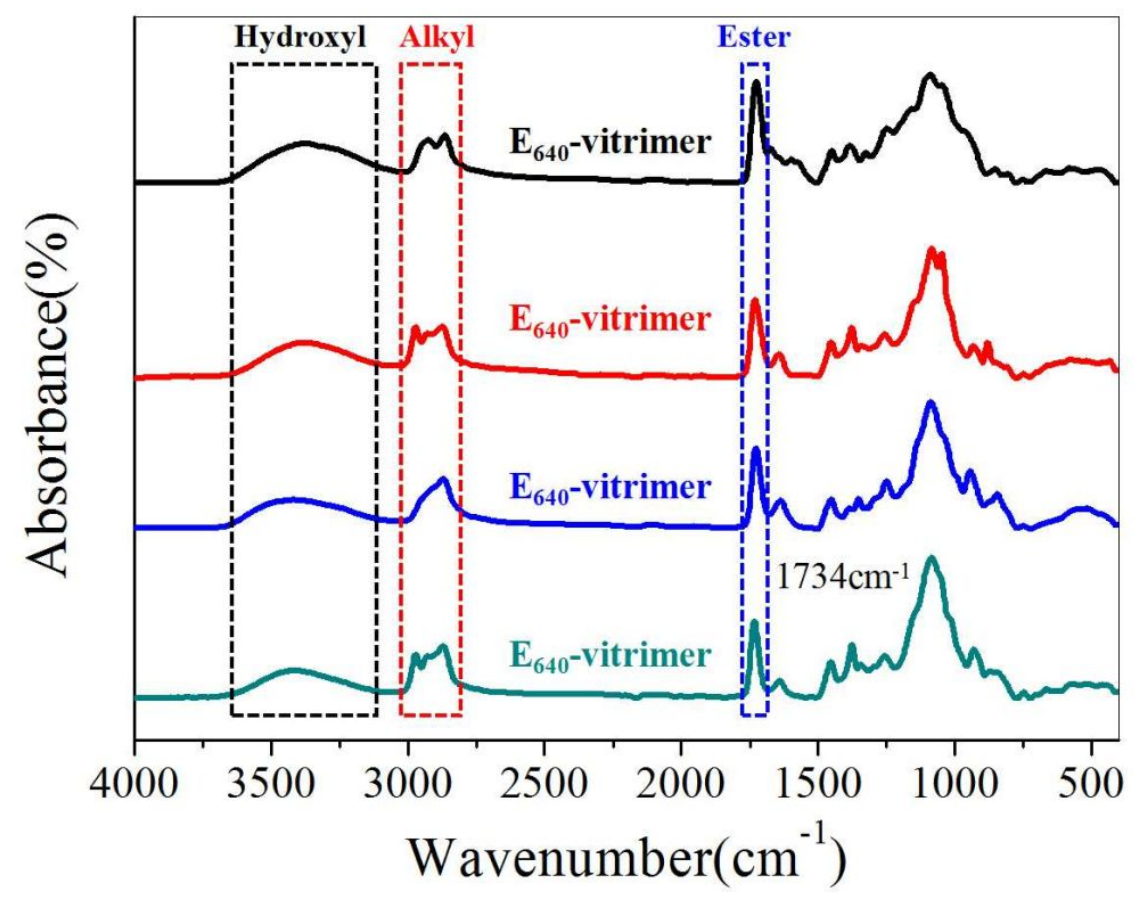

Figure S1. The FTIR absorbance spectra of the $\mathrm{E}_{202}$-vitrimer, $\mathrm{E}_{380^{-}}$-vitrimer, $\mathrm{E}_{500^{-}}$-vitrimer and $\mathrm{E}_{640}$-vitrimer.

Table S1. The relative density of ester and hydroxyl groups calculated from FTIR 
absorbance spectra by semi-quantitative analysis.

\begin{tabular}{|c|c|c|c|}
\hline Epoxy vitrimers & $\begin{array}{c}\text { Relative density of } \\
\text { ester, } \mathrm{R}_{\text {ester }}\end{array}$ & $\begin{array}{c}\text { Relative density of } \\
\text { hydroxyl, } \mathrm{R}_{\text {hydroxyl }}\end{array}$ & $\mathrm{R}_{\text {ester }}: \mathrm{R}_{\text {hydroxyl }}$ \\
\hline $\mathrm{E}_{202}$-vitrimer & 2.6319 & 0.8814 & 2.986 \\
\hline $\mathrm{E}_{380}$-vitrimer & 1.9145 & 0.7117 & 2.690 \\
\hline $\mathrm{E}_{500}$-vitrimer & 1.8529 & 0.5791 & 3.199 \\
\hline $\mathrm{E}_{640}$-vitrimer & 1.6258 & 0.5254 & 3.094 \\
\hline
\end{tabular}

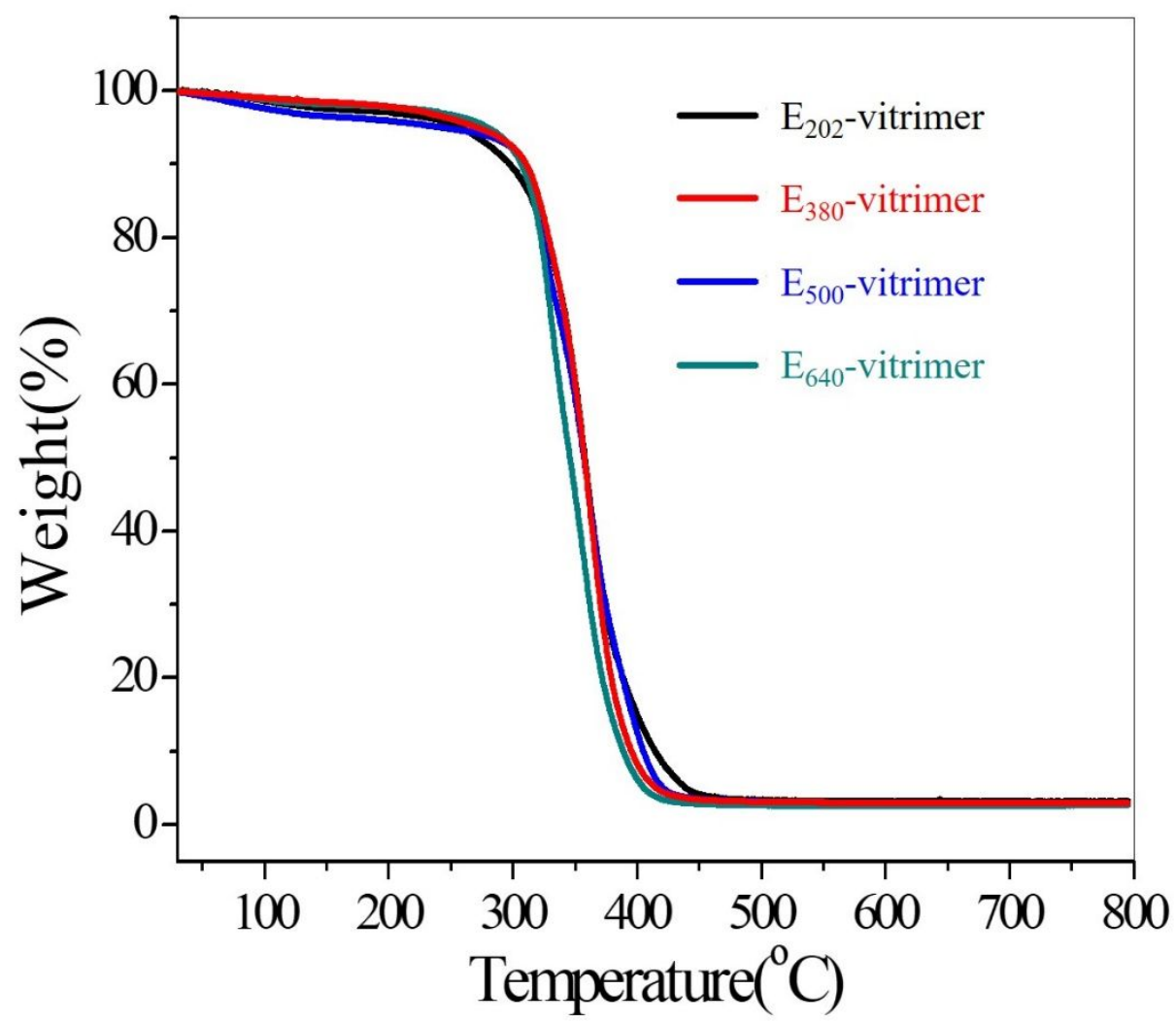

Figure S2. The TGA curves of the $\mathrm{E}_{202}$-vitrimer, $\mathrm{E}_{380}$-vitrimer, $\mathrm{E}_{500}$-vitrimer and $\mathrm{E}_{640}$-vitrimer.

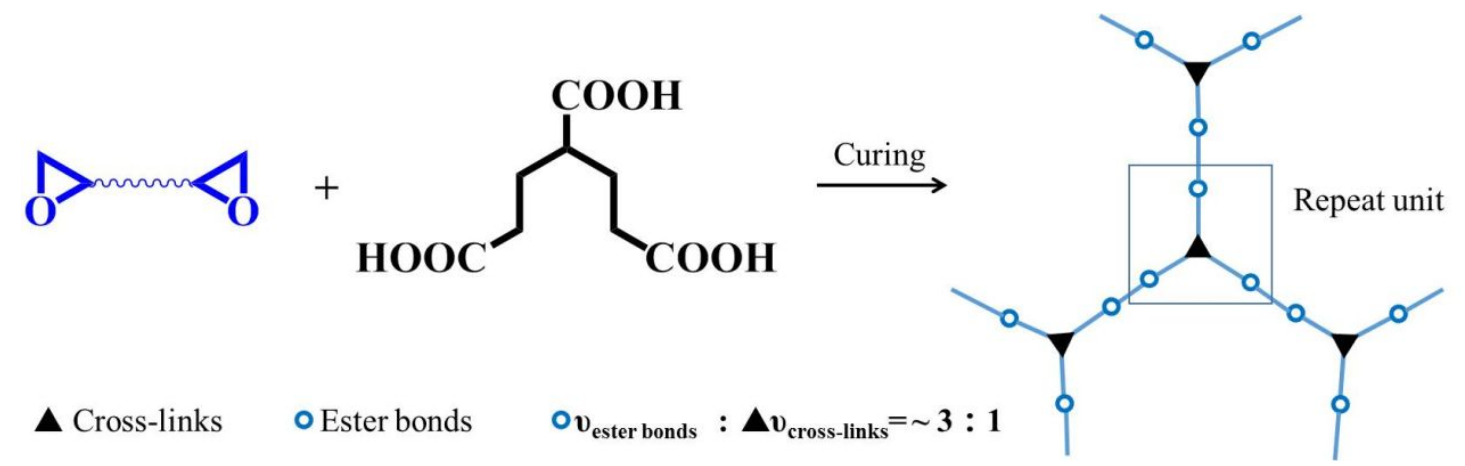

Figure S3. The ideal relationship between the $v_{\text {cross-links }}$ and $v_{\text {ester bonds }}$ in the polyester-based epoxy vitrimers. 